\title{
Contracting Out Local Government Services: A Comparative Study of Two New Zealand Regional Councils
}

\author{
Anne McLeod and Priya A Kurian
}

\begin{abstract}
Studies of New Zealand's public sector reforms since the mid-1980s have tended to focus on the application of New Public Management princtples to the central govemment. Yet local government in New Zealand too has experienced drastic restructuring with a view to ensuring greater rationalisation, efficiency and effectiveness. This article examines contracting out in New Zealand local government, focusing on the delivery of plant pest management by Environment Waikato (the Watkato Regional Counct) and the Wellington Regtonal Councl. The study rezeals distinct differences in approach by the two counctls, determined in each case by pragmatic responses to situational context rather than mere adherence to NPM principles.
\end{abstract}

\section{Introduction}

Since the mid-1980s, New Zealand, like a number of other western countries, has embarked on a major overhaul of its public sector. These reforms, commonly described as "new public management" (NPM), have shared similar goals, namely, to improve effectiveness and efficiency, enhance customer responsiveness, reduce public expenditure, and improve managerial accountability. A primary means for achieving these goals has been contracting out, based on the presumption that functioning like the private sector is inherently more cost effective and efficient. Indeed, contracting out has become the measure of efficiency for many services once delivered by the public sector. ${ }^{1}$

In New Zealand, the NPM reforms have not been limited to central government. Structural and functional reform of local government has also been undertaken applying the principles of NPM. One aspect of this reform in local government has been a shift in the delivery of some services from council departments to private contractors.

While there is a growing body of literature that examines the application of NPM in New Zealand (see, eg, Boston 1995; Boston et al 1996; Easton 1997), case studies of contracting out local authority services are limited, especially studies that go beyond examining the delivery of outputs and look at some of the process issues associated with contracting out. Examining the process issues and the rationale for contracting out allows 
an analysis of whether decisions to contract out have been driven by an ideological commitment to NPM or other contextual, pragmatic reasons. This article examines contracting out in New Zealand local government, focusing on the delivery of plant pest management - a regulatory service - by Environment Waikato (the Waikato Regional Council) and the Wellington Regional Council.

A special feature of plant pest management at Environment Waikato is that the delivery of this service is contracted out and has been ever since the Council was formed in 1989. While contracting out is not new for local authorities, what is unusual is that a regulatory service - a service that in the past would have been regarded as something that could only be performed by in-house staff - has been contracted to external service providers.

This article examines the reasons why Environment Waikato chose contracting out as its preferred method of service delivery. Was it a conscious decision to adopt alternative methods based on NPM principles, or was the decision largely shaped by the circumstances at the time? For comparative purposes, plant pest management at the Wellington Regional Council is also examined. Wellington, like the other regional councils, delivers its plant pest management services using in-house staff. The article draws on an analysis of documents, including relevant legislation, minutes of council meetings, local government reports, and in-depth interviews with the chief executives and bio-security managers of Environment Waikato and the Wellington Regional Council. ${ }^{2}$

It is important to understand some of the events that framed the decision of Environment Waikato and the Wellington Regional Council on how best to deliver plant pest management services. Before discussing the reasons for their respective decisions, we offer a brief background to plant pest management prior to the reorganisation of local government in 1989.

\section{Background}

Prior to local government reorganisation in 1989, the eradication of plant pests ${ }^{3}$ was the responsibility of all local authorities. Acting in their capacity as district noxious plants authorities (DNPAs) under the Noxious Plants Act 1978, local authorities were required to draw up, publicise and enforce district control programmes, advising land occupiers of their legal obligations for controlling classified plants. The activities of the DNPAs were co-ordinated at the national level by the Noxious Plants Council. Eradication of Class A noxious plants was the responsibility of the Ministry of Agriculture and Fisheries (Ministry of Agriculture and Fisheries 1989: 9).

In the mid-1980s, the control of noxious plants was primarily seen as a ruxal rather than an urban issue. District control programmes focused on 
pastoral plant pests such as blackberry, gorse and ragwort - pests that threatened the security of New Zealand's agricultural industry. This strong agricultural focus meant that noxious plants control was one of the "bread and butter" functions of councils. In addition, the management of noxious plants was seen as a local issue requiring local knowledge.

Two major events occurred in the late 1980 s which changed the management of plant pests in New Zealand. These were a major reorganisation of local government, ${ }^{4}$ and the government's announcement of its intention to review all legislation relating to animal and plant pests with a view to making substantive changes.

\section{Local Government Reorganisation}

In 1988 the Local Government Amendment (No 3) Act was introduced giving substantial powers to the Local Government Commission to carry out its mission of improving local government. Improvement, the Commission believed, involved the creation of a.smaller number of units; managerially and technically stronger units; multi functional units which could perform functions efficiently and effectively; and units which reflected community needs based on existing rather than historical 'communities of interest' (Bush 1995: 85). The new structure put forward by the Commission simplified local government. United councils, catchment boards, harbour boards, and a range of ad hoc authorities were replaced by regional councils. Urban authorities and counties were replaced by territorial local authorities.

In shaping the new structure of local government, the Local Government Commission decided that noxious plants control would become one of the functions of the proposed regional councils. This decision did not find favour with many local authorities which were keen for this activity to remain at a district level. They argued that the delivery of noxious plants services was a local not a regional matter. In response to these concerns, the head of the Local Government Commission at the time, Sir Brian Elwood, commented in a speech at a seminar of leaders of transitional committees ${ }^{5}$ that "The scale of the problems being addressed, in a regulatory sense were clearly regional" (Local Government Commission 1989a). However, he also acknowledged that the delivery of these services was often localised. His solution to the dilemma was through contracting out: "I therefore think it important in this context to talk not of devolution but of contracting. The regional council will be able to contract service delivery to territorial authorities or to the market place or to both".

The Commission expected that regional councils would, on a case-bycase basis, determine whether service delivery should be contracted out or provided using their own staff. Sir Brian was very clear that, if contracting out was selected, the responsibility for noxious plants control could not be passed on to the contractors - it was to remain with the regional councils. 
He also stressed that it was not up to the Commission to instruct regional councils on how best to perform the functions allocated to them. It was up to the individual councils to make their own decisions.

Sir Brian's suggestion opened the way for regional councils to consider contracting out as an option for delivering services related to noxious plants control. It also reflected the philosophy that was being promoted at the national level at this tume of decoupling policy and service delivery (see, eg, Althaus 1997). From 1987 onwards, policy and service delivery functions of government departments were being split into separate institutional arrangements. The principle behind the separation was that agencies whose existence was linked to the continuation of a particular policy were likely to be biased in favour of that policy. Separation of these activities would avoid conflicting objectives and policy would be less open to "producer capture" (Schick 1996: 20-21).

\section{Legislative Uncertainty}

In June 1989, the then Minister of Agriculture, Colin Moyle, announced that weed and animal pest control administration would change: "The changes would mean the end of the Noxious Plants Council and the Agricultural Pest Destruction Council ... As a consequence the legislation would be reviewed and future responsibilities divided between two government departments and regional councils" (Moyle 1989).

A month after the Minister's announcement, the Ministry for Agriculture and Fisheries released a discussion document reviewing all existing legislation. At this stage it was envisaged that the proposed new legislation would encompass both plant and animal pests and would draw together existing legislation from a number of different Acts. Central government would be responsible for pests of national significance and the proposed new regional councils for pests of local significance. The discussion document reiterated the suggestion made by the Local Government Commission that regional council staff could carry out the delivery of pest management services or it could be "contracted out to private individuals, district councils or even to central government agencies as appropriate" (Ministry of Agriculture and Fisheries 1989: 5, 28).

The discussion document optimistically outlined transitional arrangements for situations where new legislation was not in place by November 1989 and for an interim period between legislation being introduced and local government policy mechanisms coming into full effect. However, the introduction of new legislation took considerably longer than originally anticipated. The Bio-security Act was not passed until 1993 and its companion legislation, the Hazardous Substances and New Organisms Act, was not enacted until 1996. When the new regional councils came into existence on 1 November 1989, there was considerable uncertainty over the plant pest management function and its future direction. 


\section{Delivery of Plant Management Services: Environment Waikato}

This legislative uncertainty contributed to the reluctance to incorporate noxious plants control fully within the structure of Environment Waikato when it came into being in 1989 after the amalgamation of thirty-eight disparate bodies, including united councils, drainage boards, pest destruction boards, and DNPAs. The transition committee decided that for the first three months of the new council's existence, noxious plants control activities would be contracted out to district councils.

This decision was prompted by the fact that the new regional council lacked familiarity and knowledge of this area of work. Prior to amalgamation most of the activities the Council was to inherit were being carried out by the two catchment boards - Waikato Valley Authority and Hauraki. However, noxious plants control was a part of the county, borough and city councils that were now reorganised to form new territorial local authorities. The institutional knowledge of plant pest control could not be easily transferred to the new regional council, as record keeping by the former authorities was limited and most of the knowledge about the function was vested in individual officers (Harris: interview).

Disentangling the costs and accountability issues associated with noxious plants control from the other operations of county councils and municipalities was another problem. Pre-1989, annual planning and reporting did not have the transparency now required by the Local Government Act and costs tended to be "lumped" together. In some cases, the staff responsible for noxious plants control also performed a range of other functions such as dog control.

The legislation relating the transfer of staff from the antecedent authorities to the new local government structures was yet another factor in the Transitional Committee's decision (Harris: interview). Under the Local Government Amendment Act (No 2) 1989 (ss 25B and 25D), all staff employed by any of the former local authorities were to be transferred to the new authorities. In addition, they were to retain the same terms and conditions of employment until 31 March 1990, unless varied by agreement. Under the reorganisation scheme for the Waikato Region, the new regional council was to take over responsibility for twelve DNPAs, which employed sixteen officers responsible for noxious plants control (Waikato Regional Transitional Committee 1989b: 12). If these officers had been transferred to the new regional council, the opportunity to reshape the way the service was delivered in the future would have been severely limited. Any changes would have meant finding new jobs for these officers elsewhere in the council with similar conditions or redundancy with substantial payments due to the length of service many of these officers had given to the former authorities. Conscious that it was unable under the reorganisation legislation to commit the new regional council to any long term decisions, the 
Transitional Committee decided that in the interim it was better to contract the new district councils to undertake noxious plants control. Once the new regional council was underway, it could then decide how best to manage this activity.

\section{Post Reorganisation}

As a new organisation, Environment Waikato was faced with the enormous task of shaping its future direction and consolidating the disparate groups that had been brought together under the one umbrella. Noxious plants control was a relatively small part of the overall activities of the new council. Rather than make a hasty decision, it seemed prudent to maintain the status quo until the new council had more time to properly consider how best to deliver this activity. The continuing uncertainty surrounding the legislation reinforced the council's reluctance to rush into any decision concerning the future delivery of noxious plants services.

At its first full meeting on 30 November 1989, the council confirmed the interim arrangements made by the Transitional Committee for contracting noxious plants control to district councils (Waikato Regional Council 1989). This was followed in January 1990 with a decision to "roll" the contracts with district councils over to the 1990/91 year, on receipt of an acceptable district programme and appropriate monitoring arrangements (Waikato Regional Council 1990). Even at this early stage the contracts with the district councils were proving less than satisfactory. Issues included delays in securing signed contracts, concern over the contract prices submitted by some districts, and pending changes in the tenure of several noxious plants officers.

Two main issues emerged for the regional council in contracting noxious plants control to the districts. The first was the lack of clanty in political accountability for noxious plants control. Some district councils continued to maintain a political involvement in the management of noxious plants control. They did not see it as simply a contractual arrangement where they were to supply specific services determined by the contract principal the regional council. The public was also confused about who had responsibility for noxious plants control. They saw district council staff undertaking these tasks and assumed that it was still a district council role (Waikato Regional Council 1991)

The second issue related to the way in which noxious plants control services were being delivered. There was a feeling that the noxious plants officer positions were ill defined, with a heavy emphasis on advice and education as opposed to enforcing compliance with legislation. As well as giving advice, they were involved in "making sure that the district council's road verges had been sprayed ... often dealing with wandering stock and the occasional animal pest matter" (Simmons: interview). Possibly because 
of their close connections with the local community there appeared to be a "marked reluctance to come down hard on any individual that was in a non compliance situation" (Simmons: interview). From the regional council's perspective, the services appeared inefficient with sixteen officers serving the Waikato Region.

The regional council was reluctant to take over the service delivery itself. If it did so, staff from the districts would transfer to the regional council. This could perpetuate rather than challenge the culture that was apparent at the district level. In addition, the regional council would assume responsibility for redundancy payments should there be any changes in staffing levels.

After several rounds of interim arrangements with a number of district councils and deliberation on various options, Environment Waikato in 1991 decided to open up the service delivery to open market individual contracts. The reasons given for selecting this option were "imperfection in lines of accountability and cost effectiveness" (Waikato Regional Council 1992). Underlying this would have also been the concerns expressed earlier about the culture of noxious plants control in the districts and a desire to bring about a change. Although not explicitly stated, other factors that may have influenced this decision included the continued uncertainty over the introduction of new pest management legislation and the unsettling effect the then Minister for Local Government, Warren Cooper, was having on regional government at the time.

Warren Cooper believed that regional councils were unnecessary and, although he was unsuccessful in removing them from the structure of local government, he did succeed in limiting their activities (Bush 1995: 98). It was through Warren Cooper that Section 247D of the Local Government Act was amended in 1992, restricting regional councils to only employing staff in situations where the advantages outweighed other options.

District councils were advised of the regional council's decision to contract out plant pest management service delivery at a meeting of chief executives on 3 February 1992. Several of the councils expressed extreme concern over the decision. Matamata-Piako District Council in particular was vocal in its opposition to the decision and the manner in which it was made. In a letter to the regional council, the Mayor of Matamata-Piako District Council stated: "I believe the whole ambit of the Regional/Territorial relationship, and all parties to it, is totally at risk if this attitude is permitted to continue"6.

The Institute of Noxious Plants Officers also expressed concern over the decision. In particular, they were concerned about the lack of clear and measurable objectives in the contract documents which, it believed, would result in inconsistencies throughout the region and make it difficult to measure performance; the loss to the industry of experienced staff as the contracts would reduce the number of staff from fifteen to ten; and the 
emphasis on regulation rather than more proactive programmes which could result in an increase in plant pest problems. ${ }^{7}$

Despite the opposition, the regional council called for registrations of interest and tenders for service. In April 1992, tenders were approved for seven contract areas for a two-year period. Overall, there were considerable financial savings for the council in opting for this method of service delivery. However, these savings were largely the result of the reduction in the number of officers required to service the region. By reducing the number of contracts from eleven to seven, greater efficiencies were achieved.

Environment Waikato has continued to use competitive tendering as the basis for contracting out plant pest management. Contracts are usually for a two-year period, with a right of renewal for a further two years subject to satisfactory performance. Of the original sixteen noxious plants officers who were employed by the district councils at the time of amalgamation, only two went on to contract to the regional council. Although one district council was successful in securing a contract in the first round of competitive tendering, it did not seek renewal once it had expired.

\section{Delivery of Plant Management Services: Wellington Regional Council}

\section{Pre Reorganisation}

Urlike Environment Waikato, the Wellington Regional Council was not entirely the product of the 1989 reorganisation of local government. Its beginnings lay in the Labour Government's attempts in 1974 to reshape local government by introducing a structure of regional government centred on regional and united councils (Mulgan 1997: 198). Created in 1980, the former Wellington Regional Council had nine years to lay the foundation for a system of regional government in the Wellington area. However, this does not mean that the new Wellington Regional Council that came about through the 1989 reorganisation was the same as its predecessor. With the addition of the Wairarapa and Kapiti Coast, it changed from almost exclusively servicing an urban population to include a substantial portion of rural hinterland. Its functions were also expanded to include the role of harbour board, maritime planning authority, and noxious plants and animal pest control (Local Government Commission 1989b: 11).

Although not as far reaching as in other parts of the country, the reorganisation was not all "plain sailing". Separated from the Wellington urban area by the Rimutaka ranges, the Wairarapa was reluctant to become part of a region with which it had little affinity. Prior to the reorganisation schemes being finalised, pressure was placed on the Local Government Commission for the Wairarapa to have its own regional council rather than being absorbed into an expanded Wellington region. However, the former Wairarapa local authorties became entangled in other issues and the matter was eventually dropped (O'Donnell: interview). 
In relation to noxious plants control, two main factors influenced the way in which this function became incorporated into the regional council structure. The Wellington Regional Council was to take over responsibility for six DNPAs (Local Government Commission 1989b). Together, the former county, borough and city councils employed nine noxious plants officers, although only five actually transferred to the regional council.

While, as in other parts of the country, territorial local authorities in the Wellington area were anxious to retain noxious plants control as one of their functions, the Wellington Regional Council argued that a regional perspective would be more effective than continuing a fragmented approach. Although they were not immediately successful in changing the minds of the territorial local authorities, the control of the plant pest "old man's beard" provided "good selling point" for a regional perspective (O'Donnell: interview). Prior to amalgamation, the Wellington City Council was the only territorial local authority that did not have "old man's beard" registered as a noxious plant. The reason for this was that the city believed that the problem was "too far gone" (O'Donnell: interview) and that it was not cost effective to register it as a pest as the problem was endemic. After reorganisation, more pressure was able to be brought to bear on Wellington city to get it to change its mind and eventually a joint application was made by the city and the region to have "old man's beard" registered. This programme provided a practical demonstration that so much more could be done to control this pest with the regional council's bigger resource base than through the individual efforts of the territorial local authorities. "Over time and once they [territorial local authorities] had become a little more informed ... they could see the benefit that the regional council ... could actually bring and generally agreed" (O'Donnell: interview).

\section{Post Reorganisation}

Prior to amalgamation, the DNPAs tended to favour an educative approach to noxious plants control. While the regional council was comfortable with this approach, there was a shift toward large scale direct control programmes using Taskforce Green workers ${ }^{8}$ and a focus on single issues tather than servicing geographic areas. The bigger resource base of the regional council largely brought about this shift. However, education and advice were still two main components of the overall programme at this time.

The noxious plants officers who were taken on by the regional council initially underwent a "steep learning curve". Their numbers had been reduced from nine to five at amalgamation, and they had to take on new areas of responsibility. Several of them were a "little bit negative" toward having to make changes and there was some staff turnover" (O'Donnell: interview).

The "old man's beard" programme was a particular focus in the early 
years of the new regional councl. Once the council had succeeded in having "old man's beard" declared a noxious plant in Wellington city, a substantial proportion of the resources for noxious plants control were directed toward its eradication

Like other regional councils, the Wellington Regional Council carried out a Section 247D analysis of service delivery, required by the Local Government Amendment Act (No 2) 1992. Although not directly responsible for noxious plants staff at this time", regulatory services were probably considered far less in-depth than the utility service functions, as these were more production related and could be more easily delivered by an external provider (O'Donnell: interview). The Wellington Regional Council has continued to undertake an annual Section 247D assessment of the delivery of its various functions. ${ }^{10}$ Following this initial study, Wellington's position in relation to plant pest management has not changed.

The big change in the way plant pest management is delivered in the Wellington region occurred when the council adopted the Regional Plant Pest Management Strategy in 1996. This strategy was prepared under the new Bio-security Act passed in 1993. It represented a shift away from a focus on agricultural pests to pests that posed a threat to the environment. Other regional councils went through similar shifts, but in Wellington the move was possibly more noticeable. A number of the plant pest officers were reluctant to make the change. "They still focused on those old noxious plants which were predominantly agricultural, so there was this unwillingness to let go this bit of history". However, having the plant pest officers involved in the development of the Regional Plant Pest Management Strategy was an important component in developing commitment to its implementation. While there were differences of opinion during its preparation, the plant pest officers "all bought into the strategy and became part of its delivery". The Wellington Regional Council's bio-security officials believe that the same commitment cannot always be achieved when a service is contracted out: "There's a risk I believe that if you're not involved in policy development or have the opportunity to influence it ... then you might have this degree of apprehension or slight resistance as to why you are doing some of this work" (O'Donnell: interview).

The Wellington Regional Council currently employs eight full-time staff to carry out its plant pest management activities. Although the Wairarapa accounts for 75 percent of the land within the Wellington region, only two plant pest officers have responsibility for servicing this area, operating from the council's offices in Masterton. The remaining six are based in Upper Hutt. This split between the two offices reflects the shift in focus from agricultural to environmental pests brought about by the Regional Plant Pest Management Strategy, as a high proportion of the environmental pests are found in the wooded hills and gullies of the greater Wellington urban area. Those working out of the Upper Hutt Office service all land west of 
the Rimutaka/Tararua ranges up to the region's northern boundary at Otaki. With the exception of the three officers responsible for the "old man's beard" programme in Wellington city, the remaining staff are encouraged to work as a team rather than in separate geographic areas. This enables the council to pool its resources for certain issues and during certain seasons. Flexibility, therefore, is a further reason for favouring the employment of staff in-house as opposed to contracting out (O'Donnell: interview).

\section{Contrasting Administrative Positions}

Comparing the delivery of plant pest management services at Environment Waikato with the Wellington Regional Council reveals three distinct differences in approach. The first relates to the separation between policy and service delivery (decoupling); the second to addressing issues of culture; and the third to the way services have been structured (geographical versus an issues-based approach).

\section{Decoupling}

One of the fundamental principles of local government reform laid down in the government's December 1987 Economic Statement was that "authorities should have clear non-conflicting objectives" and that "tradeoffs between objectives should be seen as a separate objective" (Horner 1989: 3). According to Horner (1989: 3), this suggests that "institutional arrangements should separate service delivery functions and regulatory functions" leaving the organisation less open to capture by pressure groups. The principle of decoupling that had been applied to state owned enterprises and was beginning to be applied to the public sector, with the separation of policy ministries from delivery agencies and regulatory from commercial functions, was now being applied to local government. Early in the reform process, the government had considered the idea of making territorial local authorities solely responsible for service delivery and regional councils totally responsible for regulation. This idea was later rejected as it was recognised that there were some service delivery functions that were best carried out by regional councils ( $\mathrm{eg}$, bulk water supply) and some regulatory activities were best performed by territorial local authorities (eg, health inspection bylaws). There was also a feeling that separation could be achieved within each local authority (Horner 1989: 8). This concept of decoupling was later enshrined in legislation. Section $223 \mathrm{C}$ of the Local Government Act requires that:

Every local authority ... shall, in conducting its affairs, ensure that 
(d) So far as practicable, its regulatory functions are separated out from its other functions...

(h) So far as practicable, its management structure reflects and reinforces the clear separation of regulatory functions from other functions ..."'ll

It is unclear from the legislation whether the term regulatory function is only making rules and regulations, or whether it also includes monitoring and enforcement. While there are some elements of noxious plants control that could be classified as service delivery (eg, public awareness campaigns), monitoring and inspection activities could fall into either category. However, it would appear that the Local Government Commission viewed the activities of noxious plants officers as service delivery, and that it was possible to separate out their activities from the making of rules and regulations, although the final decision was left up to the local authority concerned.

The principle of decoupling in some ways legitimated Environment Waikato's decision to contract out noxious plants control to the districts and later private contractors, but it was clearly not the reason for making the decision. It was a pragmatic decision based on a range of different factors, none of which had anything to do with NPM. Legislative uncertainty, a lack of familiarity with the function, and a desire to change the culture of this work area were the main reasons to opt for contracting out. It was coincidental that the decision reflected the government's policy directions for local government reform.

At the time of local government reorganisation, the Wellington Regional Council's position was different to Environment Waikato's. Although it faced the same legislative uncertainty, it had significant experience in regional government. Besides, it had to accommodate only nine officers within the new council structure (as opposed to Waikato's sixteen), and it had fewer concerns about the methods used to deliver noxious plants control services. It also seemed to be clear about the value it could add to noxious plants control. By combining the resources of the former authorities under the regional council structure, it was able to tackle much larger issues, avoiding the fragmentation that could occur if it was left to the districts.

In a report prepared on local government in 1995, the New Zealand Business Roundtable recommended that the issue of decoupling needed to be re-examined. They maintained that "there is potential for conflicts of interest between the service delivery interests of councils and their regulatory functions, despite the internal separation of such functions". Their suggestions for remedying the problem were for all regulatory activities to be undertaken by regional councils or for "directly elected regulatory entities to service cities and districts and for existing territorial councils to provide 
only services other than regulatory services" (New Zealand Business Roundtable 1995: 77).

The principle of decoupling is a two-edged sword. On the one hand, separating policy development from delivery or implementation reduces the risk of capture. On the other hand, developing policy in isolation from those charged with implementation may result in policies which are unworkable or have unintended consequences. There is also the issue of policy implementers creating new policy through their action. Decoupling assumes that policy implementers will be motivated for reasons of selfinterest to deliver services in accordance with the policy developer's demands. Following through the Wellington Regional Council's argument for involving the plant pest officers in the policy development process, the commitment of those delivering services to the specifics of the policy is vital for successful implementation. However, there are several ways in which policy implementers can and should be involved in the policy development process without having to be employed as in-house staff. During the preparation of its Regional Pest Management Strategy, Environment Waikato seconded several of its plant pest contractors onto the Strategy Project Team (Environment Waikato 1996: 127). In addition, other plant pest officers were able to contribute to the strategy in the same way as Environment Waikato staff did.

What should the basis be for determining how a service should be delivered? From Environment Waikato's perspective, contracting out private sector delivery and market forces should not be the driving force for determining service delivery methods. There will be times when these methods will provide a better service than an in-house operation, but they do not automatically mean better services. "The mistake a lot of people I believe make in moving toward what is the best means of service delivery is not understanding what on earth it is that they are supposed to be delivering". In the first instance effort should be on "being clear strategically about why we are here and what is it that our community requires us to deliver ... then ... move onto what's the best delivery mechanism" (Harris: interview).

\section{Culture}

One of the reasons for Environment Walkato selecting contracting out as the preferred method of service delivery was in part a concern over the culture of plant pest management in the former district councils. The regional council thought that the noxious plants officer positions were ill defined, and that there was an imbalance with a heavy emphasis on advice and education rather than ensuring legislative compliance.

Commenting on the reforms of the state sector in New Zealand, Matheson (1997: 165-170) notes that for a public service that seemed 
"unresponsive to political direction..., contracts turned out to be a catalyst for fundamental change ... [Contracting] triggered a major process of interactions among public servants and between public servants and ministers which led to unscrambling of muddled purposes and clarification of hitherto unclear roles" The same could be argued in relation to the competitive tendering of plant pest management. It enabled Environment Waikato to make extensive changes to the way services were delivered and to improve efficiency. No longer restricted by district council boundaries, Environment Waikato was able to rationalise services by reducing the number of contracts from eleven to seven. With the reduction in contracts came a reduction in the number of personnel required to service the region. Immediately there were savings - tangible evidence from the council's point of view of improved efficiency.

Through contracting, Environment Waikato also gained greater control over the balance between the different activities performed by the plant pest officers. The council was able to specify how time should be spent and to require a greater level of inspection and enforcement. While these changes may have been achieved if the service had been delivered in-house, they may not have been accomplished with the same speed. In addition, at the time the decision was made to move to competitive tendering, there was still considerable uncertainty over the future of regional councils and the shape of the new bio-security legislation. By contracting out the service, the council was less exposed.

Like Environment Waikato, the Wellington Regional Council needed to address issues of culture associated with the delivery of plant pest management. The introduction of the Bio-security Act and the development of the Regional Plant Pest Management Strategy changed the direction of the Bio-security Department and some staff were reluctant to make this change. Unlike Environment Waikato, the concern was not about the way in which services were being delivered, but the type of plant pests to be managed. Some officers strongly believed that the pastoral plant pests that they had been managing for years still needed the same level of attention that they had been given in the past and were reluctant to switch their focus to environmental pests.

Changing organisational culture can be achieved through a variety of means. One method is changing the way in which services are delivered, thereby forcing new approaches to be taken. However, processes used to affect change need not always be so radical. Other methods include quality management programmes designed to introduce operational improvements and engender a spirit of continuous improvement. The Wellington Regional Council consciously chose to involve its plant pest management staff in its policy development process with a view to bringing about a change in culture and securing staff commitment to any changes in policy direction. While the process may have been slower, Wellington officials believe it has 
been worthwhile, as it has helped ensure "buy-in" by staff members, as well as assisting in developing a team approach to plant pest management (O'Donnell: interview).

\section{Structure}

In convincing territorial local authorities of the benefits of regional involvement in noxious plants control, the Wellington Regional Council, through its "old man's beard" programme, was able to demonstrate the advantages of tackling common issues rather than managing plant pests within defined geographic boundaries. This approach avoided the problem of fragmentation and enabled the council to concentrate its effort on a small number of plant pests where invasiveness posed a significant threat to the region. Another advantage of taking an issue approach rather than a geographic approach to plant pest management was that it provided flexibility, allowing the skills of different officers to be utilised on a range of projects (O'Donnell: interview).

In contrast to the Wellington Regional Council, Environment Waikato takes a geographic approach to plant pest management. This approach reflects the size of the Waikato Region (25,000 square kilometres ${ }^{12}$ as opposed to the Wellington Regional Council's 8,130 square kilometres ${ }^{13}$ ). It is also likely to reflect the view expressed by the districts prior to reorganisation that noxious plants control is a local not a regional matter. By dividing the region into contract areas, Environment Waikato is able to maintain a local presence through the plant pest contractors and also ensure the contractors are an identifiable personality in their areas. One of the disadvantages of this approach is that all contractors must be skilled in every aspect of plant pest management. For example, they must be a skilled educator and public speaker, as well as having skills in conflict resolution and technical knowledge of bio-control methods.

The geographic approach lends itself to contracting out. Contract areas can be clearly defined along with the activities to be undertaken within these areas. Issue-based projects such as the Wellington Regional Council's "old man's beard" programme could be contracted out to external providers because of its clearly defined parameters ${ }^{14}$. However, contracting out could not be applied as easily to smaller, less defined issues without losing some of the flexibility that can be achieved through the employment of in-house staff.

\section{Conclusion}

Environment Waikato's decision to contract out plant pest management to the private sector was not based on NPM theories and principles. It was a pragmatic decision based on the circumstances and priorities at the time. 
However, NPM provided a backdrop to the decision, making the contracting out of regulatory activities a more acceptable method of service delivery than it may have been previously.

The contrasting experiences of Environment Waikato and the Wellington Regional Council in deciding how best to deliver plant pest management services suggests that, rather than being based on any theory, decisions of this sort will reflect the circumstances at the time and the council's objectives. It is essential to be clear about the work to be done, the objectives to be achieved, and the external factors likely to affect the delivery of services. Once these matters have been determined, then decisions can be made about the most appropriate method of service delivery. Decoupling and contracting out clearly should not be the driving force behind the service delivery method selected.

Because of the different variables to be taken into account, it is not possible to assume that, because contracting out has suited the delivery of plant pest management in the Waikato region, this model can necessarily be transferred to other regional councils. Conversely, when examining service delivery methods for activities such as plant pest management, contracting out should be one of the methods regional councils seriously consider.

\section{Notes}

1. It is worth noting that recent studies on contracting out have been contradictory. For instance, Domberger and Jensen's (1997) overview of contracting out shows cost savings of up to 20 percent without sacrificing the quality of service provided. In contrast, Ohlsson (2003) found that contracted out refuse collection service in Sweden cost significantly more than those provided by local government. Clearly, assumptions about automatic efficiency through contracting out need to be tempered. 2. Much of the data for this study was collected in 2000 as part of a larger study on local government in New Zealand.

3. Since the introduction of the Bio-security Act 1993, noxious plants have been referred to as plant pests. The terms are used interchangeably here.

4. Since the reforms of the 1980s, a new Local Government Act came into force in December 2002. The 2002 Act moves away from the prescription of the earlier Act and provides local communities with more scope to make choices about what their local authority does and how it does it. Perhaps in keeping with new political realities of a Lobor Party-led government, the new Act has begun a shift away from strict adherence to NPM principles. A key change under the 2002 Act is the lifting of the restrictions on the type of activities regional councils can perform. Previously, the activities of regional councils were lumited to functions specified in legislation. Under the new Act, regional councils have the power of general competence similar to district councils. In addition, the presumption under section 247D of the old Act was that regional councils could not use their own staff to deliver services unless they were satisfied that the advantages to ratepayers outweighed other options. 
This presumption has now been lifted and there is not the same imperative to consider contracting out

5. Transitional committees were established to prepare for the transition to the new local authorities on 1 November 1989.

6. Letter from the Mayor of Matamata-Piako District Council to Waikato Regional Council dated 18 February 1992.

7. Letter from the Institute of Noxious Plants Officers to Waikato Regional Council dated 31 March 1992.

8. Taskforce Green is a government employment scheme which provides shortterm job opportunities for disadvantaged job seekers on projects of environmental or community benefit.

9. The Wellington Regional Council's Bio-security Department was not formed until January 1994.

10. Rather than assessing all functions every year, Environment Waikato selects different areas for in-depth study.

11. The new Local Government Act 2002 has to a degree relaxed the stringent separation of regulatory and non regulatory activities, focusing more on a separation at the governance level.

12. Environment Waikato, 1999/00 Annual Plan, p. 2.

13. Wellington Regional Council, Facting The Future 1997-2007: 1999 Update \& 1999/ 2000 Anntial Plan. Wellington, p. 11.

14. While Wayne O'Donnell agreed that this programme could be contracted out, he noted that the whole job needed to be considered, as there were some aspects of this project that would not be suited to contracting out.

\section{References}

Althaus, C 1997, "The Application of Agency Theory to Public Sector Management", in G Davis, B Sullivan, \& A Yeatman (eds), The New Contractualssm, Melbourne: Macmillan Education Australia Ltd.

Boston, J 1995,"Inherentiy Government Functions and the Limits to Contracting Out", in J Boston (ed), The State Under Contract, Wellngton: Bridget Williams Books Ltd.

-.-., Martin, J, Pallot, J, \& Walsh, P 1996, Public Management: The New Zealand Model, Auckland: Oxford University Press.

Bush, G 1995, Local Government and Politics in New Zealand, 2nd ed, Auckland. Auckland University Press.

Domberger,S \& Jensen, P 1997, "Contracting Out by the Public Sector: Theory, Evidence and Prospects", Oxford Review of Economic Policy, 4.

Environment Waikato 1996, Regional Pest Management Strategy: Operattve 1996 - 2001. Hamilton (August 1996). 
The Asta Pacific Journal of Public Administration

-..- 1999/00 Annual Plan, Hamilton.

Harris, B 2000, Chief Executive, Environment Waikato, interview.

Horner, T 1989, "Local Government Reform: Links to Public Sector Reform", Public Sector, 12(3) New Zealand Institute of Public Adminstration (September 1989).

Local Govermment Act 1974, Section $223 \mathrm{C}(1)(\mathrm{d})$ and (h).

Local Government Commission 1989a, Report on a Semmar Regional Transtional Committee Leaders, Wellington, April 1989.

Local Government Commission 1989b, Final Reorganisation Scheme for the Wellington Region, Wellington, June 1989.

Matheson, A 1997, "The Impact of Contracts on Public Management in New Zealand", in G Davis, B Sullivan \& A Yeatman'(eds), The New Contractualism, Melbourne: Macmillan Education Australia Ltd.

Ministry of Agriculture and Fisheries 1989, Revtew of Weed and Antmal Pest Management Leguslation: Discusston Document, Wellington, July 1989.

Moyle, C 1989, Press Release. Ministry of Agriculture and Fisheries. 19 June 1989 (unpublished).

Mulgan, R 1997, Polttics in New Zealand, 2nd ed, Auckland: Auckland University Press.

New Zealand Business Roundtable 1995, Local Government in New Zealand: An overview of economic and financial issues. Wellington (January 1995).

O'Donnell, W 2000, Biosecurity Manager, Wellington Regional Council, interview.

Ohlsson, H 2003, "Ownership and Production Costs: Choosing between Public Production and Contracting-Out in the Case of Swedish Refuse Collection", Fiscal Studies, 24(4).

Schick, A 1996, The Spirit of Reform: Managing the New Zealand State Sector in a Time of Change, Wellington: State Services Commission.

Simmons, J 2000, Bio-security Group Managet, Environment Waikato, interview.

Waikato Regional Council 1989, Council Minutes. Hamilton, November 1989.

---1990, Council Minufes. Hamilton, January 1990.

..-1991, Memorandtum from the Chief Executtve to all Regional Councillors, Hamilton, 12 July 1991. 
---- 1992, Counct Minutes. Hamilton, 27 February 1992.

Waikato Regional Transitional Committee 1989b, Report On The Local Authorittes Constituting The Proposed Waikato Regional Council, Hamilton, April 1989.

Wellington Regional Council 2000, Facing The Future 1997-2007: 1999 Ulpdate \& 1999/ 2000 Annual Plan, Wellington.

Anne McLeod is the Deputy Chref Executive Office of the Taupo Distruct Councll, and Prya Kurtan is Sentor Lecturer, Department of Polttcal Sctence and Public Policy, Universtty of Waikato, New Zealand. 